\title{
Lymphocytic Mastitis and Diabetic Mastopathy: A Molecular, Immunophenotypic, and Clinicopathologic Evaluation of 11 Cases
}

Riccardo Valdez, M.D., John Thorson, M.D., William G. Finn, M.D., Bertram Schnitzer, M.D., Celina G. Kleer, M.D.

Department of Pathology, University of Michigan Medical School (RV, WGF, BS, CGK), Ann Arbor, Michigan; and University of Texas Health Sciences Center at San Antonio (JT), San Antonio, Texas

Lymphocytic mastitis and diabetic mastopathy are uncommon fibroinflammatory breast diseases. The lesions seen in these entities are unique in that the associated lymphoid infiltrates are composed of predominantly B cells. In addition, B-cell lymphoepithelial lesions, a finding commonly associated with extranodal marginal zone B-cell/mucosaassociated lymphoid tissue (MALT) lymphomas, are also often present in lymphocytic mastitis and diabetic mastopathy. Although the clinical and immunomorphologic features are well characterized, the clonality of the B-cell infiltrate and the lymphomatous potential of lymphocytic mastitis and diabetic mastopathy have not been emphasized in the literature. We evaluated 11 cases of lymphocytic mastitis/diabetic mastopathy for immunoglobulin heavy chain gene rearrangement and correlated the findings with all available clinical data. A longstanding history of Type I diabetes mellitus was present in seven patients. One nondiabetic patient had Sjogren's syndrome, and two patients had no history of diabetes mellitus or other autoimmune disease. Clinical data were unavailable for one patient. B-cell-predominant lymphoid infiltrates were seen in all cases, and B-cell lymphoepithelial lesions were found in five. No evidence of a B-cell clone was found in any of the 11 cases by appropriately controlled immunoglobulin heavy chain gene rearrangement studies, and none of the patients developed lymphoma during follow-up intervals ranging from 2-126 months. These findings suggest that despite the presence of B-cell-predominant lymphoid

Copyright () 2003 by The United States and Canadian Academy of Pathology, Inc.

VOL. 16, NO. 3, P. 223, 2003 Printed in the U.S.A

Date of acceptance: December 7, 2002.

Address reprint requests to: Riccardo Valdez, M.D., Department of Pathology, University of Michigan Medical School, M5242 Medical Sciences Bldg. I, 1301 Catherine Street, Ann Arbor, MI 48109-0602; fax: 734-9362756; e-mail: rcdovldz@umich.edu.

DOI: 10.1097/01.MP.0000056627.21128.74 infiltrates and lymphoepithelial lesions, lymphocytic mastitis and diabetic mastopathy do not appear to be associated with an increased risk for lymphoma.

KEY WORDS: B-lymphocytes, Diabetic mastopathy, Gene rearrangement, Lymphepithelial lesions, Lymphocytic mastitis.

Mod Pathol 2003;16(3):223-228

Lymphocytic lobulitis, ductitis, and perivasculitis with stromal fibrosis constitute an uncommon fibroinflammatory breast lesion that often presents as a discretely palpable uni- or bilateral mass. This lesion typically occurs in women (and rarely in men) with either longstanding Type I diabetes mellitus (diabetic mastopathy) or other types of autoimmune disease (lymphocytic mastitis) (1-4). The clinicopathologic criteria for establishing a diagnosis of lymphocytic mastitis and diabetic mastopathy have been well characterized and described in the literature $(5,6)$. Briefly, routinely stained sections of involved breast tissue typically show dense keloidlike parenchymal fibrosis with epithelioid fibroblasts and prominent perivascular, periductal, and perilobular infiltrates of small lymphocytes with variable numbers of scattered plasma cells. Infiltration of the epithelium by small lymphocytes, resulting in lymphoepithelial lesion formation, has also been documented by some authors. In addition, immunohistochemical studies have demonstrated that the lymphoid infiltrates in lymphocytic mastitis and diabetic mastopathy, including the lymphocytes forming the lymphoepithelial lesions, are composed of predominantly B lymphocytes $(2,6$, 7). These findings are unusual and intriguing because most reactive lymphoid infiltrates in other epithelial tissues are composed of mostly $\mathrm{T}$ cells and also because B-cell lymphoepithelial lesions are most often associated with extranodal marginal 
zone B-cell/mucosa-associated lymphoid tissue (MALT) lymphomas.

The clinicopathologic features of lymphocytic mastitis and diabetic mastopathy, including the natural history of these lesions with respect to recurrence after biopsy, have been thoroughly examined (5); however, the association of these lesions with B-cell non-Hodgkin's lymphoma has been reported only rarely (8-10). Moreover, the clonality of the lymphoid infiltrate in these lesions has not been previously evaluated. In this study, we investigated 11 cases of lymphocytic mastitis/diabetic mastopathy for evidence of an immunoglobulin heavy chain gene rearrangement, using DNA extracted from archival formalin-fixed, paraffin-embedded tissue and the polymerase chain reaction technique, to determine whether the B cells in lymphocytic mastitis/diabetic mastopathy are clonal. All available clinical data were also reviewed for any evidence of lymphoma or lymphoproliferative disorder before, at, or after the diagnosis of lymphocytic mastitis/diabetic mastopathy was made to determine whether an association between these lesions and B-cell non-Hodgkin's lymphoma could be found.

\section{METHODS AND MATERIALS}

\section{Case Identification and Immunohistochemistry}

The surgical pathology records of the University of Michigan Health System (Ann Arbor, MI) were searched for all cases reported as lymphocytic mastopathy or mastitis, diabetic mastopathy or mastitis, and/or fibrous mastopathy from January 1990 through August 2001. Routinely processed hematoxylin and eosin-stained sections were independently reviewed by two of the authors (R.V. and C.G.K), and 11 cases fulfilling published criteria for a diagnosis of lymphocytic mastitis or diabetic mastopathy $(5,6)$ were selected for further study.

Immunohistochemical stains for CD3 epsilon (DAKO Corporation, Carpinteria, CA; titer, 1:50) and CD20 (DAKO; titer, 1:500) were performed on formalin-fixed, paraffin-embedded sections of all 11 cases using previously described methods (11). In addition, an immunostain for CD43 (DAKO; titer, $1: 25)$ was done in the five cases with lymphoepithelial lesions to exclude aberrant coexpression of this marker on the B-cell infiltrate.

\section{Gene Rearrangement Studies}

All 11 cases were analyzed for immunoglobulin heavy chain gene rearrangement; blocks with the most representative lesional tissue were selected for these studies. Three cases of known B-cell nonHodgkin's lymphoma (including one case of ex- tranodal marginal zone B-cell lymphoma) and 5 cases of breast carcinoma with marked lymphocytic infiltrates were also sent as positive and negative control samples, respectively. The gene rearrangement studies and result analyses were performed using the following methods.

\section{Extraction of DNA from paraffin-embedded tissue}

Five sections of $10-\mu \mathrm{m}$ thickness were cut from each formalin-fixed, paraffin-embedded tissue sample and placed into $1.5-\mathrm{mL}$ microfuge tubes. The sections were deparaffinized by washing twice in 800- $\mu \mathrm{L}$ of Citrisolv (Fisher Scientific, Pittsburgh, PA), followed by three washes in $800-\mu \mathrm{L} 100 \%$ ethanol. After the final ethanol wash, the tissue specimens were dried by placing the tubes in a heating block at $55^{\circ} \mathrm{C}$ for 30 minutes. To the dried specimens, $100 \mu \mathrm{L}$ of TEN buffer (10 mM Tris-HCL, $\mathrm{pH}$ 8.0, $1 \mathrm{~mm}$ EDTA, $20 \mathrm{~mm} \mathrm{NaCl}$ ) containing 200 $\mu \mathrm{g} / \mathrm{mL}$ Proteinase $\mathrm{K}$ were added. After overnight incubation at $55^{\circ} \mathrm{C}$, the samples were incubated at $95^{\circ} \mathrm{C}$ for 10 minutes and then processed by centrifuge. The supernatant containing extracted DNA was transferred to new tubes and stored at $-20^{\circ} \mathrm{C}$ before analysis.

\section{Polymerase chain reaction analysis of immunoglobulin gene rearrangement}

For PCR analysis of immunoglobulin heavy chain gene rearrangements, $1 \mu \mathrm{L}$ of each extracted DNA specimen was used as a template for amplification in a $50-\mu \mathrm{L}$ reaction volume containing $20 \mathrm{~mm}$ of Tris- $\mathrm{HCl}, \mathrm{pH} 8.4 ; 50 \mathrm{~mm}$ of $\mathrm{KCl} ; 2 \mathrm{~mm}$ of $\mathrm{MgCL}_{2} ; 0.2$ mM each of deoxynucleotide triphosphate (Perkin Elmer, Wellesley, MA), 50 pmol of each primer (framework III primer 5'-ACACGGCC(T/C)GT(A/ G)TATTACTGT-3'; JHa primer 5'-ACCTGAGGAGACGGTGACC-3'), and $1 \mathrm{U}$ of Amplitaq Gold (Perkin Elmer). Separate control reactions were set up using normal human tonsil DNA or DNA from a patient sample (D99-377) known to contain a polyclonal population of B cells (negative controls), a mixture of 5\% Raji Burkitt cell lymphoma DNA in 95\% normal human tonsil DNA (positive sensitivity control), and blank reactions containing all reagents except template DNA (background control). Thermal cycling was carried out in a Perkin Elmer GeneAmp PCR System 9700 instrument (Perkin Elmer, Wellesley, MA), as follows: $95^{\circ} \mathrm{C}$ for 10 minutes (preheat step to activate Amplitaq Gold) followed by 45 cycles of $95^{\circ} \mathrm{C}$ for 45 seconds (denature), $55^{\circ} \mathrm{C}$ for 1 minute (anneal), and $72^{\circ} \mathrm{C}$ for 1 minute (extension).

\section{Analysis of results}

An aliquot $(45 \mu \mathrm{L})$ of each PCR product was analyzed by electrophoresis on a $3.5 \%$ agarose gel using $0.5 \times$ TBE buffer and the resulting band pat- 
tern visualized by ethidium bromide staining and ultraviolet transillumination. Photographs of each gel were obtained as a permanent record of the results. Interpretation of the band patterns was performed by a pathologist (JAT): samples exhibiting a smearing pattern between 100 and $120 \mathrm{bp}$ without any distinct bands were judged to be negative for a clonal rearrangement of immunoglobulin heavy chain genes. Samples exhibiting one or two crisp bands in the 100- to 120-bp region, with or without a smear of polyclonal bands in the background, were judged to be positive for a clonal rearrangement of immunoglobulin heavy chain genes.

The results of the immunomorphologic and molecular studies were correlated with all available clinical data including history, pertinent laboratory findings (including complete blood cell and platelet counts and white blood cell differential counts), and radiographic examinations, which were obtained by comprehensive chart review.

\section{RESULTS}

All 11 cases of lymphocytic mastitis/diabetic mastopathy occurred in women ranging from 30-81 years of age (mean, $43.8 \mathrm{y}$; Table 1 ). Seven of 10 patients had longstanding Type I diabetes mellitus, with the majority having documented secondary complications, most commonly renal insufficiency, with one patient requiring a renal transplant for end-stage renal disease several months after diabetic mastopathy was diagnosed. One of the 11 patients had a history of Sjögren's syndrome (uncomplicated by lymphoma), but otherwise, none of the patients had a documented history of other autoimmune disorders. Two patients with complete histologic features of lymphocytic mastitis/diabetic mastopathy had no documented history of either diabetes mellitus or other autoimmune disease. Sufficient clinical data to exclude diabetes mellitus or autoimmune disease were available for one patient.
The morphologic criteria for a diagnosis of lymphocytic mastitis/diabetic mastopathy were met in each of the 11 patients (Fig. 1). Ten patients presented with a unilateral fibrous mass for which an excisional biopsy was performed in 9, and multiple core biopsies in 1. Lymphocytic mastitis/diabetic mastopathy was found in a reduction mammoplasty specimen in one patient. In all cases, routine hematoxylin and eosin-stained sections showed keloid-like fibrosis with epithelioid fibroblasts found in 5 of 7 patients with diabetes mellitus and in the 1 case for which clinical data were unavailable (Case 8). Prominent lymphocytic infiltrates involving breast ducts and lobules were present in every case; perivascular lymphocytic infiltrates were seen in 4 of 11 specimens. In every case, the cells composing the lymphoid infiltrates were predominantly small lymphocytes with only rare larger cells and scattered plasma cells identified in a few cases. The lymphocytes lacked atypical morphologic features, and there was no morphologic evidence of monocytoid differentiation in any of the cases. Follicular structures and/or germinal centers were absent. Immunostains for CD3 epsilon and CD20 were performed on each specimen and, in eight cases, demonstrated that the lymphoid infiltrates consisted of a marked predominance of small $\mathrm{B}$ cells with only few scattered $\mathrm{T}$ cells (Fig. 2). T lymphocytes were slightly more numerous in the other three cases; however, B cells predominated in these cases as well. Extensive lymphocytic infiltration of the epithelia forming lymphoepithelial lesions was found in five cases (Fig. 3). An immunostain for CD43 was performed on these five cases with lymphoepithelial lesions, and all cases were negative for aberrant expression of this antigen on the B-cell population. The constellation of clinical, morphologic, and immunophenotypic findings was fully consistent with lymphocytic mastitis/diabetic mastopathy, as described in previous reports.

Polymerase chain reaction-based studies for immunoglobulin heavy chain gene rearrangement us-

TABLE 1. Summary of Patients Evaluated and Selected Results

\begin{tabular}{|c|c|c|c|c|c|c|c|c|}
\hline Case & Age/Sex & $\begin{array}{l}\text { Diabetes } \\
\text { Mellitus }\end{array}$ & $\begin{array}{c}\text { Other Autoimmune } \\
\text { Disease }\end{array}$ & $\begin{array}{l}\text { Peripheral Blood } \\
\text { Lymphocytosis }\end{array}$ & LELs & $\begin{array}{c}\text { IgH Gene } \\
\text { Rearrangement Result }\end{array}$ & Lymphoma & $\begin{array}{l}\text { Follow-Up Interval } \\
\text { (months) }\end{array}$ \\
\hline 1 & $38 / \mathrm{F}$ & Type I & None & No & Yes & Negative & No & 6 \\
\hline 2 & $32 / \mathrm{F}$ & Type I & None & No & No & Negative & No & 18 \\
\hline 3 & $43 / \mathrm{F}$ & Type I & None & No & No & Negative & No & 93 \\
\hline 4 & $46 / \mathrm{F}$ & Type I & None & Unknown & Yes & Negative & No & 126 \\
\hline 5 & $33 / \mathrm{F}$ & Type I & None & Unknown & Yes & Negative & No & 5 \\
\hline 6 & $44 / \mathrm{F}$ & Type I & None & No & Yes & Negative & No & 79 \\
\hline 7 & $51 / \mathrm{F}$ & No & None & No & No & Negative & No & 79 \\
\hline 8 & $38 / \mathrm{F}$ & Unknown & Unknown & Unknown & Yes & Negative & No & 70 \\
\hline 9 & $81 / \mathrm{F}$ & No & Sjogren's syndrome & No & No & Negative & No & 33 \\
\hline 10 & $46 / \mathrm{F}$ & No & None & No & No & Negative & No & 71 \\
\hline 11 & $30 / \mathrm{F}$ & Type I & None & No & No & Negative & No & 2 \\
\hline
\end{tabular}

LELs = lymphoepithelial lesions; IgH = immunoglobulin heavy chain. 


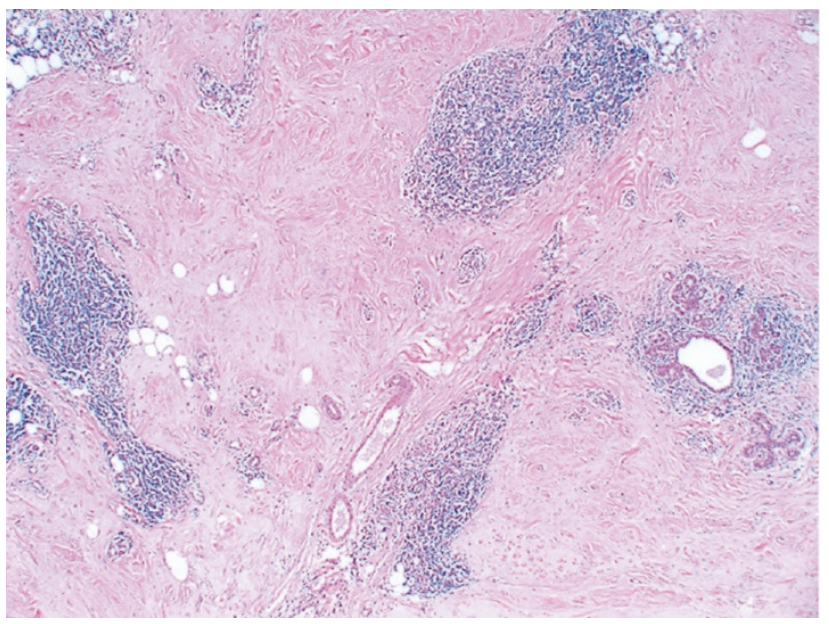

FIGURE 1. Lymphocytic mastitis/diabetic mastopathy characterized by keloid-like fibrosis and prominent lymphocytic infiltrate surrounding breast ducts and lobules.
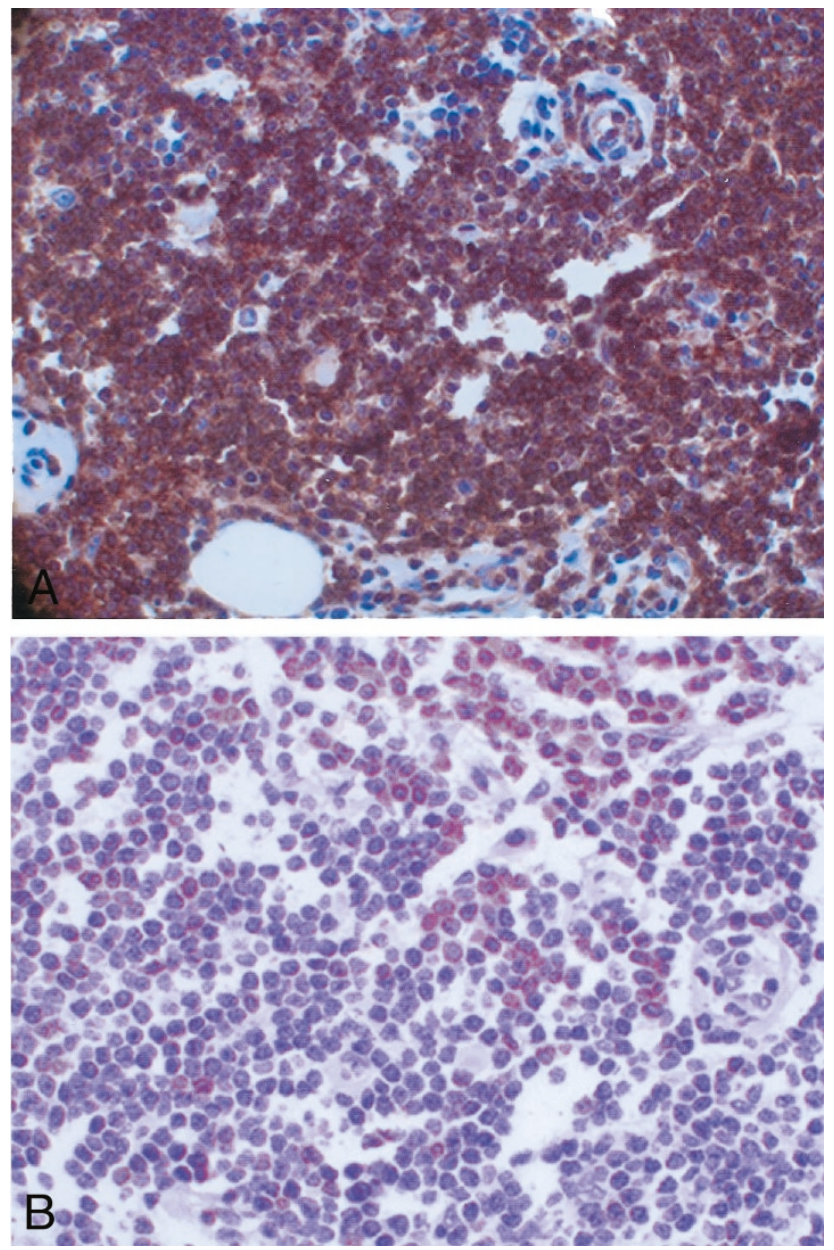

FIGURE 2. Immunostains for CD20 (A) and CD3 epsilon (B) from a typical case of lymphocytic mastitis/diabetic mastopathy showing a marked B-cell predominance in the lymphoid infiltrate.

ing DNA isolated from archival formalin-fixed, paraffin-embedded tissue were performed for all 11 cases, and no evidence of immunoglobulin heavy chain gene rearrangement was found in any of the

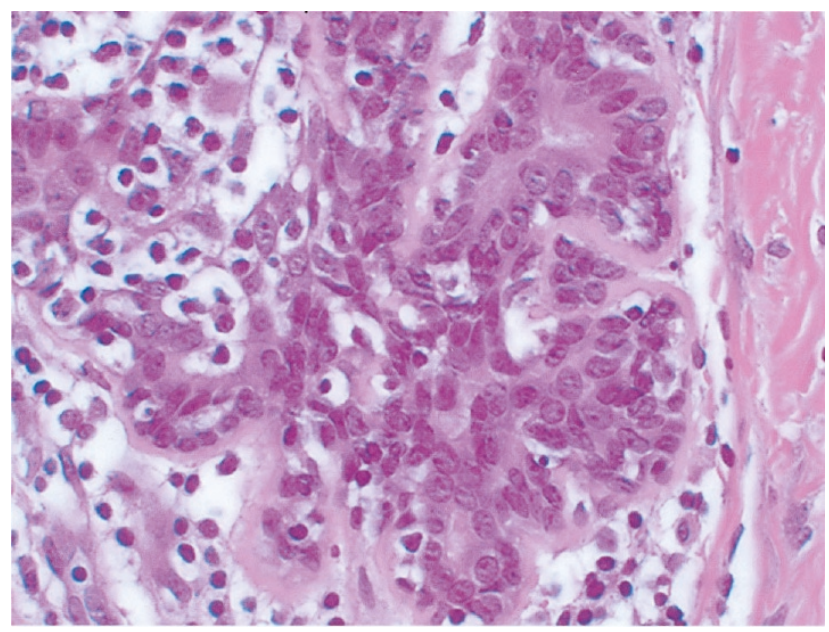

FIGURE 3. Extensive infiltration of breast epithelium by small lymphocytes. These had a B-cell phenotype (CD20 positive by immunohistochemistry)

cases (Fig. 4). Three cases of previously diagnosed and well-documented B-cell non-Hodgkin's lymphoma (including one case of extranodal marginal zone B-cell lymphoma of MALT) and five cases of breast carcinoma (two invasive ductal carcinoma, one lobular carcinoma, and two medullary carcinomas) with heavy lymphocytic infiltrates were also subjected to immunoglobulin heavy chain gene rearrangement analysis by the same method. Clonal immunoglobulin heavy chain gene rearrangement was detected in all three cases of known B-cell non-Hodgkin's lymphoma but not in any of the breast carcinomas (Fig. 4).

Comprehensive review of the available clinical data revealed that none of the patients were diagnosed with lymphoma before or at the time that lymphocytic mastitis/diabetic mastopathy was diagnosed. In addition, none of the patients developed lymphoma during a mean follow-up period of 52.9 months (range, 2-126 mo; median, 70 mo). Documented physical examinations revealed no evidence of adenopathy in any of the 11 patients.

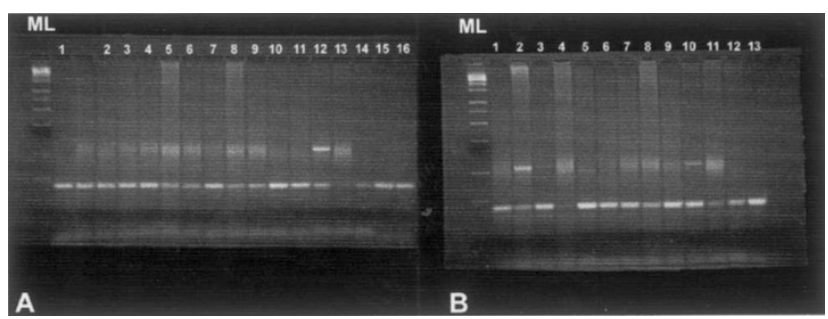

FIGURE 4. Electrophoresis gels showing results of PCR-based immunoglobulin heavy chain gene rearrangement studies. A, Lanes 111, lymphocytic mastitis/diabetic mastopathy patients; Lane 12, positive control (5\%); Lanes 13-14, negative controls; Lanes 15-16, reagent controls (no DNA). B, Lanes 1, 4, and 6-8, breast carcinomas; Lanes 2, 3, and 5, B-cell lymphomas involving breast; Lanes 9 and 11, negative controls; Lane 10, positive control (5\%); Lanes 12-13, reagent controls (no DNA). ML = molecular ladder. 
Complete blood cell counts, including differential white blood cell counts, were performed in eight patients, and none had an absolute lymphocytosis in the peripheral blood. Comprehensive radiographic studies (i.e., other than unremarkable routine chest radiographs) were routinely obtained in one patient who had received a renal transplant for end-stage renal disease secondary to diabetes mellitus, and these studies showed no lymphadenopathy. Except for the patient with clinically diagnosed Sjögren's syndrome (and excluding diabetes mellitus), none of the other patients had clinical or laboratory evidence of an autoimmune disease. Last, lymphocytic mastitis/diabetic mastopathy did not recur, and no other breast masses developed in any of the patients studied during the same follow-up period.

\section{DISCUSSION}

Lymphocytic mastitis and the closely related entity of diabetic mastopathy are uncommon benign breast diseases that are believed to be induced by autoimmune phenomena $(3,12)$. Similar to other select autoimmune-related inflammatory lesions, but distinctly unlike almost all other reactive infiltrates in epithelial tissues, the lymphoid population in these entities consists of predominantly B lymphocytes. Although it is well established that certain autoimmune conditions such as Helicobacter pylori gastritis, Hashimoto's thyroiditis, and Sjögren's syndrome are associated with B-cell non-Hodgkin's lymphoma in the stomach, thyroid gland, and salivary glands, respectively, lymphocytic mastitis/diabetic mastopathy has not been established as a premalignant lesion with certainty.

Only few authors have reported on the relationship between lymphocytic mastitis/diabetic mastopathy and B-cell non-Hodgkin's lymphoma (810). In a study of primary breast non-Hodgkin's lymphoma, which included 12 large B-cell and eight MALT lymphomas, Aozasa et al. (8) reported finding lymphocytic mastopathy in most of the cases they examined. Based on this finding, they suggested that B-cell lymphoma in the breast might be associated with coexisting or antecedent lymphocytic mastopathy, although the criteria used to diagnose lymphocytic mastitis were not reported. Another case of extranodal B-cell lymphoma involving the breasts and skin in a patient with lymphocytic lobulitis was reported by Rooney et al. (10) in a publication emphasizing the well-established relationship between extranodal lymphomas and underlying autoimmune disorders.

In our study, we investigated the lymphomatous potential of lymphocytic mastitis/diabetic mastopathy in 11 patients by searching for the following: (1) evidence of a clonal B-cell population by immunoglobulin heavy chain gene rearrangement studies (all cases); (2) evidence of aberrant expression of CD43 on B cells (cases with lymphoepithelial lesions); and/or (3) evidence of a lymphoproliferative disorder at any time in the patient's history by reviewing all available clinical, laboratory, and radiographic data. None of the data obtained indicated the presence of a B-cell lymphoproliferative disorder in our cohort of patients. All 11 cases of lymphocytic mastitis/diabetic mastopathy were negative for evidence of a clonal B-cell population by immunoglobulin heavy chain gene rearrangement studies. Although the possibility of false negative gene rearrangement results was considered, specific care was taken to perform these studies using tissue blocks containing the most significant B-cell infiltrates, and in all cases, appropriate internal control results were obtained. Moreover, identical studies on positive and negative controls yielded the expected results, indicating the validity of the testing procedure. Because one of the positive controls used in this study was a MALT lymphoma involving the breast, all materials from this specimen as well as the clinical and laboratory data were reviewed for evidence of concomitant lymphocytic mastitis/diabetic mastopathy. Although lymphoepithelial lesions were present as expected in a MALT lymphoma, the other morphologic features of lymphocytic mastitis/diabetic mastopathy (specifically the characteristic fibrosis) were absent, as was any evidence of diabetes mellitus or other autoimmune disorder.

Based on the results of the molecular and immunophenotypic studies we performed and the absence of lymphoma in all patients studied during the mean follow-up interval of 52.9 months, we suggest that lymphocytic mastitis and diabetic mastopathy do not carry a risk for the development of lymphoma, despite the marked B-cell infiltrates and the frequent presence of lymphoepithelial lesions seen in these diseases. Because others have reported finding at least lymphocytic lobulitis in patients with B-cell non-Hodgkin's lymphoma, however, further studies of this unusual entity are warranted to further define any relationship that it may have with B-cell lymphoma.

\section{REFERENCES}

1. Camuto PM, Zetrenne E, Ponn T. Diabetic mastopathy: a report of 5 cases. Arch Surg 2000;135:1190-3.

2. Hunfeld KP, Bassler R, Kronsbein H. "Diabetic mastopathy" in the male breast-a special type of gynecomastia. A comparative study of lymphocytic mastitis and gynecomastia. Pathol Res Pract 1997;193:197-205.

3. Lammie GA, Bobrow LG, Stainton MOM, et al. Sclerosing lymphocytic lobulitis of the breast-evidence for an autoimmune pathogenesis. Histopathology 1991;19:13-20.

4. Soler NG, Khardori R. Fibrous disease of the breast, thyroiditis, and cheiroarthropathy in type I diabetes mellitus. Lancet 1984;1:193-5. 
5. Ely KA, Tse G, Simpson JF, et al. Diabetic mastopathy: a clinicopathologic review. Am J Clin Pathol 2000;113:541-5.

6. Tomaszewski JE, Brooks JSJ, Hicks D, et al. Diabetic mastopathy: a distinctive clinicopathologic entity. Hum Pathol 1992; 23:780-6.

7. Hunfeld KP, Bassler R. Lymphocytic mastitis and fibrosis of the breast in long-standing insulin-dependent diabetics: a histopathologic study on diabetic mastopathy and report of ten cases. Gen Diagn Pathol 1997;143:49-58.

8. Aozasa K, Ohsawa M, Saeki K, et al. Malignant lymphoma of the breast. Immunologic type and association with lymphocytic mastopathy. Am J Clin Pathol 1992;97:699-704.
9. Lee AH, Mills RR, Bobrow LG. Primary lymphoma of the breast and lymphocytic lobulitis. Histopathology 1994;25:297-8.

10. Rooney N, Snead D, Goodman S, et al. Primary breast lymphoma with skin involvement arising in lymphocytic lobulitis. Histopathology 1994;25:297-9.

11. Tworek JA, Singleton TP, Schnitzer B, et al. Flow cytometric and immunohistochemical analysis of small lymphocytic lymphoma, mantle cell lymphoma, and plasmacytoid small lymphocytic lymphoma. Am J Clin Pathol 1998;110:582-9.

12. Schwartz IS, Strauchen JA. Lymphocytic mastopathy. An autoimmune disease of the breast? Am J Clin Pathol 1990;93: 725-30.

\section{Book Review}

\section{Smoller BR: Practical Immunopathology of the Skin, 208 pp, Totowa, NJ, Humana Press, 2002 (\$129.50).}

As the ever-increasing torrent of information accumulates regarding immunopathology, a need for texts that abstract this body of knowledge grows. Practical Immunopathology of the Skin is a well-scripted monograph that does just this with specific regard to the practice of dermatopathology. The text is divided into three main sections: 1) introduction, 2) antibody directory, and 3) case vignettes. The book itself is in a compact handbook form, making for quick, easy reference.

The introductory section includes two chapters. The first chapter gives an overall purview of immunopathology, including some well-placed paragraphs discussing the when, where, who, and why(s) of the discipline. The second chapter is a concise but highly readable overview of immunopathology technique. This particular chapter would be at home in a major surgical pathology text and is recommended reading to anyone who needs a primer course on how immunologic staining works.

The antibody directory section covers a wide gamut of antibodies. Photographs are provided showing typical staining patterns. Most of the photos are black and white save for a few color plates; however, this does not detract considering that most immunologic staining methods are limited to one signal color. A format of introduction, diagnostic utility, technical considerations, and summary section is provided for each antibody. This method is rigorously adhered to and allows for rapid gathering of information. It is worth noting that the background details for each antibody are directed toward specific dermatologic diagnoses. The uses for the antibodies outside of the skin are not extensively elaborated upon. The book concludes with a series of case vignettes that illustrate and teach the uses of the myriad antibodies discussed throughout the previous text.

Overall, this book would be a valuable addition for pathology and dermatology residents, fellows and practicing pathologists, dermatologists, and dermatopathologists who would like a practical resource for contemporary dermatologic immunopathology.
Jay C. Helsel
Midwest Pathology Associates
Kansas City, Missouri 